\title{
Microbiology Susceptibility LOINC Code
}

National Cancer Institute

\section{Source}

National Cancer Institute. Microbiology Susceptibility LOINC Code. NCI Thesaurus. Code C87933.

A sequence of characters that identifies microbiology susceptibility data within the Logical Observation Identifiers Names and Codes (LOINC) database. 